\title{
EFFECT OF POST WELD AGING TREATMENT ON TENSILE PROPERTIES OF GTAW WELDED ARMOUR GRADE AA2519-T87 ALUMINIUM ALLOY JOINTS
}

\author{
R.Sokkalingam $^{1}$, K.Venkatesan ${ }^{2}$, S.Sree Sabari $^{3}$, S.Malarvizhi ${ }^{4}$, V.Balasubramanian ${ }^{5}$ \\ ${ }^{I}$ Assistant Professor, Department of Mechanical Engineering, Knowledge Institute of Technology, Salem Tamilnadu, \\ India \\ ${ }^{2}$ Assistant Professor, Department of Metallurgical Engineering, Government College of Engineering, Salem, Tamilnadu, \\ India \\ ${ }^{3}$ Research Scholar, Centre for Materials Joining and Research (CEMAJOR), Department of Manufacturing Engineering, \\ Annamalai University, Annamalai Nagar 608 002, Tamil Nadu, India \\ ${ }^{4}$ Associate Professor, Centre for Materials Joining and Research (CEMAJOR), Department of Manufacturing \\ Engineering, Annamalai University, Annamalai Nagar 608 002, Tamil Nadu, India \\ ${ }^{5}$ Professor, Centre for Materials Joining and Research (CEMAJOR), Department of Manufacturing Engineering, \\ Annamalai University, Annamalai Nagar 608 002, Tamil Nadu, India
}

\begin{abstract}
AA2519-T87 aluminium alloy is newly developed armour grade, age hardenable alloy with best mechanical properties, high impact toughness and ballistic resistance properties Because of this beneficial property it is preferable in replacement of steels in the light combat vehicles in order to reduce the weight and improves mobility. Formation of oxide layers, solidification cracking and porosity creates problems in the fusion welding of aluminium alloys. Gas tungsten arc welding (GTAW) is widely used fusion welding process for joining aluminium alloys which results improved arc stability, reduced thermal distortion, reduced residual stress and spatter free joints. By proper controlling of process parameters of GTAW, sound weld joint is achieved at welding current of 145 A, welding speed of $2 \mathrm{~mm} / \mathrm{s}$, and voltage of $16 \mathrm{~V}$. Due to heating and rapid cooling cycles, the weld joints properties deteriorated due to loss of precipitates and uneven distribution of precipitates. In order to recover the lost properties, post weld aging treatments are carried. In this investigation the effect of post weld aging treatments like artificial aging $\left(120^{\circ} \mathrm{C}\right.$ for 12 hours) and solution heat treatment $\left(530^{\circ} \mathrm{C}\right.$ for $\left.90 \mathrm{~min}\right)$ followed by artificial aging are evaluated. The microhardness and tensile properties are evaluated and characterized using optical microscope and scanning electron microscope for the three welding condition
\end{abstract}

Keywords: AA2519-T87 aluminium alloy, gas tungsten arc welding, post weld aging treatments, microstructure, tensile properties, microhardness

\section{INTRODUCTION}

Customers of any kind always looking forward cost reduction, that can be accompanied by reduction in fuel consumption and maintenance cost and providing more service life. Fuel consumption can be minimized by reducing the mass of vehicles. Effective method of reducing mass is lowering the density of material inspite of increasing properties such as yield strength, young's modulus, etc.,[1] and maintenance cost can dropped down by improving or optimizing the mechanical properties. Thus aluminium alloys with low density and high strength replaces steel in many applications because of their better mechanical behavior, ready availability of manufacturing procedures and inspecting techniques and so we can design reliable reasonable costing light weight end products. Off that 2000 series aluminium alloys found their applications in areas where good fatigue crack growth resistance and more damage tolerance is required. With some magnesium alloying element it can attain high strength due to precipitation of $\mathrm{AlCu}_{2}$ and $\mathrm{AlCuMg}$ phases [2]. AA2519-
T87 is newly developed high strength, heat treatable aluminium alloy with good ballistic performance, stress corrosion resistance, high strength to weight ratio and high toughness that is best suited for military applications such as parts of light combat vehicle, heavy military bridge, thus finds substitute for steel[3-4]. It is impossible to develop every component as single cast, so welding plays important role in fabrication of any structures. The difficulties with the welding of the high strength aluminium alloys are formation of stable surface oxide, weld cracking or distortion due to residual stresses and high solidification shrinkage resulting from high coefficient of thermal expansion, high thermal conductivity of aluminium requires the high heat input during welding further leading to the possibility of distortion or cracking and has high solubility for hydrogen when in the molten state leads to weld porosity.

The following three welding processes from arc welding process are most commonly used [5-7] to fabricate the butt joints in high strength aluminium alloys: (i) gas metal arc 
welding (GMAW), (ii) gas tungsten arc welding (GTAW), and (iii) plasma arc welding (PAW).

Both GMAW and GTAW are preferred because of their easy applicability and better economy. The problems associated with these processes are porosity, lack of fusion, incomplete penetration and cracks. Though GMAW process offers high deposition rate, high welding speed and better penetration, some problems like melt and distortion of parent metal will occur, due to higher heat input, in thin plates of aluminium alloy, thus GTAW welding is preferable for thin plate welding and GMAW for thick plate welding[8-9].

V. Ravisankar etal showed that GTAW is most preferable process compared to GMAW and PAW for butt welding of high strength 7075 aluminium alloy using analytical hierarchical process[]. R.S Parmar in his text book showed that GTAW process best suitable for aluminium welding in aerospace, rocket and reactor applications [10].

But controlling of process parameter will results in sound defect free weld. Since this is age hardaneble aluminium alloy, joints have weld strength lower than that of parent metal because of partial or complete dissolution of strengthening precipitates [11], segregation of solute due to localized melting and coarsening of fusion zone grains at the end of rapid resolidification.

Menzmer etal investigation evaluated that microstructure coarsening in fusion zone is due to slow dissipation of heat during welding [12] and Lakshminarayan etal concluded that coarse columnar grains in fusion zone leads to sharp decrease in joint strength than that of parent metal[13].

One of the technique used efficiently to regain lost properties of precipitate age hardaneble alluminium alloy by modifying size, shape and distribution of strengthening precipitate or by reprecipitation of second phase alloy, is post weld heat treatment (PWHT), [14]. Many literature were available on the PWHT of various age hardenable alloy like 7075, 6061, 2219, etc [15-19]. Yet no author reveals the effect of PWHT of AA2519 T87 aluminium alloy. Hence an investigation is made to study the effect of post weld heat treatment on tensile properties of GTAW welded AA 2519 - T87 armour grade aluminium alloy. The mechanical properties like tensile and hardness were correlated with the microstructural features of various PWHT conditions.

\section{INVESTIGATION METHODOLOGY}

The rolled plate of age hardenable AA 2519 aluminium alloy in T87 temper condition was used for the investigation and is machined to size of $75 \times 150 \times 4 \mathrm{~mm}$ to do square butt welding using machines like abrasive cutter, conventional lathe, shaping machine, grinding machine, etc., The parent metal was subjected to spectro chemical analysis, tensile test and Vickers microhardness test to verify its chemical composition and mechanical properties and their results were tabulated as shown in table 1 and table 2 respectively.
Table 1: Chemical composition of AA2519-T87 aluminium alloy

\begin{tabular}{|l|l|l|l|l|}
\hline $\begin{array}{l}\mathbf{S i} \\
\mathbf{\%}\end{array}$ & $\begin{array}{l}\mathbf{F e} \\
\mathbf{\%}\end{array}$ & $\begin{array}{l}\mathbf{C u} \\
\mathbf{\%}\end{array}$ & $\begin{array}{l}\mathbf{M n} \\
\mathbf{\%}\end{array}$ & $\begin{array}{l}\mathbf{M g} \\
\mathbf{\%}\end{array}$ \\
\hline 0.040 & 0.102 & 5.709 & 0.262 & 0.471 \\
\hline $\begin{array}{l}\mathbf{C r} \\
\mathbf{\%}\end{array}$ & $\mathbf{V}$ & $\mathbf{P b}$ & $\mathbf{T i}$ & $\begin{array}{l}\mathbf{A l} \\
\mathbf{\%}\end{array}$ \\
\hline 0.0017 & 0.056 & $<0.005$ & 0.029 & 93.32 \\
\hline
\end{tabular}

Table 2: Mechanical properties of AA2519 -T87 aluminium alloy

\begin{tabular}{|l|l|l|l|}
\hline $\begin{array}{l}\text { 0.2 \% } \\
\text { Yield } \\
\text { strength } \\
\text { (MPa) }\end{array}$ & $\begin{array}{l}\text { Ultimate } \\
\text { tensile } \\
\text { strength } \\
\text { (MPa) }\end{array}$ & $\begin{array}{l}\text { Elongation } \\
\text { in 50 mm } \\
\text { gauge } \\
\text { length (\%) }\end{array}$ & $\begin{array}{l}\text { Micro } \\
\text { hardness } \\
\text { (HV) }\end{array}$ \\
\hline 427 & 452 & 11.2 & 161 \\
\hline
\end{tabular}

Semi automatic GTAW setup was used to weld the aluminium plates. By trial and error method, the parameter that provide defect free weld with bead width to height ratio was taken to be optimized process parameter and these parameters were tabulated as shown table 3 and by using this optimum parameters three square butt welds to investigate weld in aswelded condition (AW) and two post weld aging conditions such as artificially aging alone (AA) and solution heat treatment followed by artificial aging (STA) were fabricated and that is shown in Fig.1.

Table 3: Optimized GTAW process parameters

\begin{tabular}{|l|l|}
\hline Process Parameters & Values \\
\hline Joint configuration, $(\mathrm{mm})$ & $75 \times 150 \times 4$ \\
\hline Automation & Mechanized \\
\hline Current & $145 \mathrm{~A}$ \\
\hline Voltage & $16 \mathrm{~V}$ \\
\hline Welding Speed & $2 \mathrm{~mm} / \mathrm{Sec}$ \\
\hline Shielding Gas & Argon Gas \\
\hline Gas Flow Rate & $20 \mathrm{Kgf} / \mathrm{cm}^{2}$ \\
\hline Filler & $\begin{array}{l}\text { Autogeneous } \\
\text { (Without Filler) }\end{array}$ \\
\hline
\end{tabular}

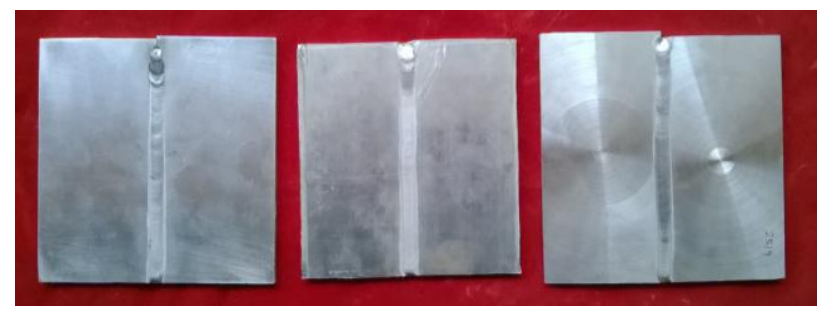

Fig. 1: Gas tungsten arc welded joints

Solution heat treatment (ST) was carried out by heating welded joint at the rate of $100^{\circ} \mathrm{C}$ per hour in induction furnace to $535^{\circ} \mathrm{C}$ and held at same temperature for soaking period of 90 minutes followed by cold water quenching and Artificial aging (AA) treatment condition was attained by by heating 
welded joint at the rate of $100^{\circ} \mathrm{C}$ per hour in induction furnace to $175^{\circ} \mathrm{C}$ and held at same temperature for soaking period of 12 hours followed by slow furnace quenching. For the solution treated and aged (STA) group of joints, both the above heat treatment procedures were followed one after the other to get the combined effect of treatments.

The $100 \mathrm{kN}$ loading capacity, Instron made servo hydraulic controlled universal testing machine was used for uniaxial tensile testing. ASTM E8M-04 standard was followed to prepare the smooth tensile specimens to evaluate the transverse tensile properties of the joints such as yield strength, tensile strength and elongation and notched specimens were prepared to evaluate notch tensile strength and notch strength ratio as given in Fig. 2.
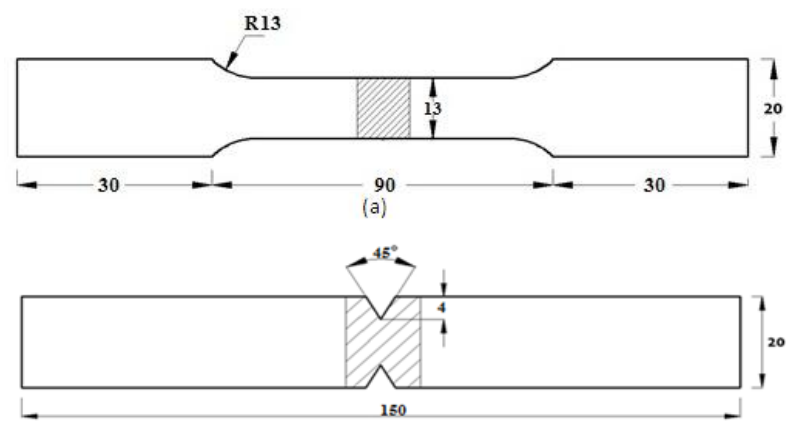

(b)

Fig. 2: Tensile specimens a) Smooth tensile specimen and b) Notched tensile specimen

A Vickers microhardness testing machine (SHIMADZU, Japan; model HMV-2T) was used to measure the hardness of the weld with a load of $0.5 \mathrm{~N}$ and dwell time of $15 \mathrm{~s}$. The microhardenss values were measured at depth of $20 \mathrm{~mm}$ along the transverse direction comprising various weld regions. Microstructural examination was carried out using an optical microscope (MEJI, Japan; model MIL-7100) incorporating image analyzing software (Metal vision). The specimens for metallographic examination were prepared by rough polishing from rough belt emery polishing to different grades of emery papers to get fine polish. Final polishing was done using alumina powder in the disc polishing machine. The specimens were etched with standard Kellers reagent as per the ASTM standard E407.

\section{RESULTS AND DISCUSSION}

\subsection{Macro and Microstructure}

The macrograph of the weldment of optimized parameters is shown in Fig. 3.

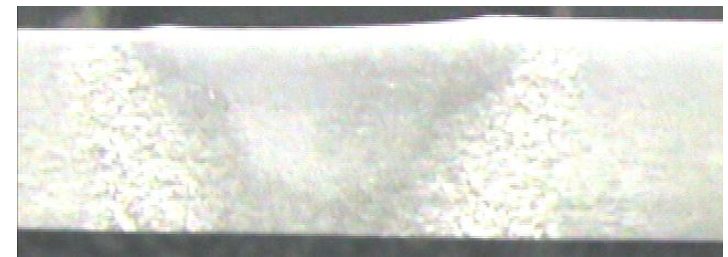

Fig. 3: Macrograph
In that macrostructure we can clearly distinguish three zones such as fusion zone(FZ), interface zone between FZ and HAZ and heat affected zone (HAZ).

The optical micrograph of the base metal and gas tungsten arc welded joints at aswelded and post weld aged condition are shown in Figs. 3 and 4. The base metal microstructure shows elongated grains towards rolling direction (Fig. 3). The fusion zone (FZ) is composed of equiaxed dendritic network (Fig. 4), where complete melting and resolidification occurs. In generally fine fusion zone microstructure is due to fast cooling rates in the weldment. Precipitation aging is limited by the formation of an eutectic constituent, at the end of solidification, which takes away of the matrix most of elements needed for precipitation reactions[20]. , But in the HAZ (Fig. 4), where dissolution of precipitate and coarsening of grain in zone occurs due to higher peak temperatures and partial dissolution of precipitate and transformation of metastable phase to stable phase in zone submitted to low peak temperature[21]. In the interface between the HAZ and FZ typical coarse columnar grain (Fig. 4) and incipient melting at grain boundaries due to the wide freezing range. We know that grain size refinement results in enhancement in strength and coarsening of grains founds decrement in its strength, Fusion zone (FZ) shows good strength while heat affected zone (HAZ) have poor strength.

Microstructures of post weld aging treated (PWHT) weld joint shows no change in its grain size but it enhances strength by reprecipitation of $\mathrm{Alcu}_{2}$. In AA condition since no homogeneous super saturated solid solution formed, it will leads to partial regain of precipitates but in STA condition, due to heating metal to solutionizing temperature homogeneous super saturated solid solution is formed and quenching in cold water bath results in formation of GP zone, increases hardness by producing local strain and further artificial aging will leads to formation of strengthening precipitate $\mathrm{Alcu}_{2}$, that is coherent with the aluminium matrix. Coherency leads to rise in stress field level thus further increases hardness and strength.

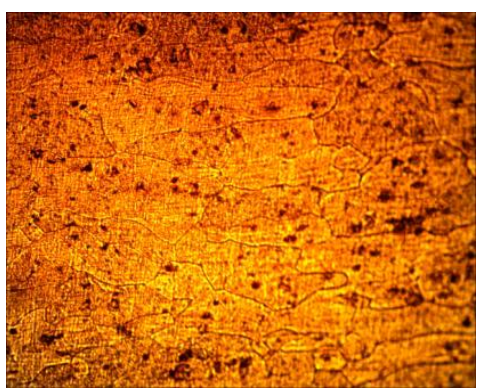

Fig. 4: Base metal micrograph 


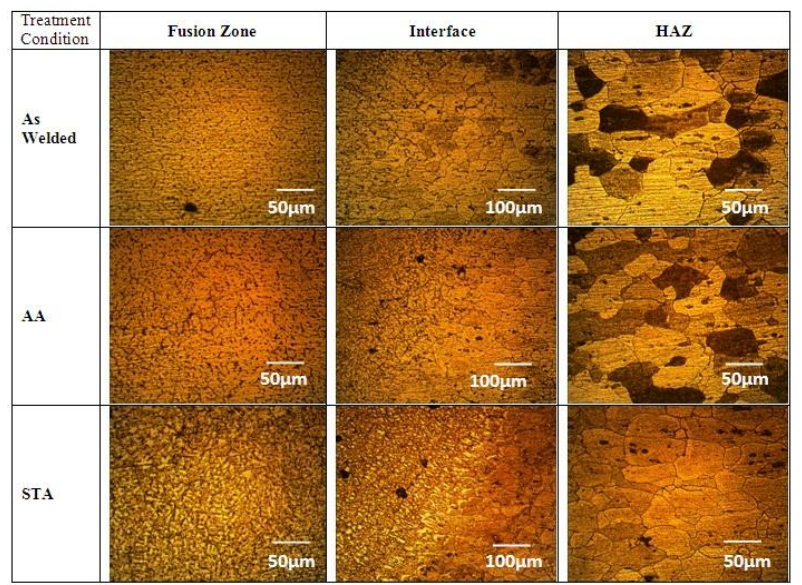

Fig. 5: Microstructure of gas tungsten arc welded AA2519 T87 aluminium alloy at as welded and Post weld aging conditions.

\subsection{Tensile Property}

The yield strength, tensile strength, \% elongation, notch tensile strength and joint efficiency were evaluated for aswelded, AA \& STA conditions and are tabulated as shown in Table 4. As welded joint posses yield strength, tensile strength, \% elongation, notch tensile strength and joint efficiency of $286 \mathrm{MPa}, 320 \mathrm{MPa}, 7.22 \%, 258 \mathrm{MPa}$ and $66 \%$ respectively and post weld aging treatment results in enhancement in tensile strength of $4.6 \%$ in AA condition and $11.8 \%$ in STA condition.

\begin{tabular}{|l|l|l|l|l|}
\hline $\begin{array}{l}\text { Joint } \\
\text { Type }\end{array}$ & $\begin{array}{l}\mathbf{0 . 2} \text { \% } \\
\text { Yield } \\
\text { Strength } \\
\text { (MPa) }\end{array}$ & $\begin{array}{l}\text { Tensile } \\
\text { Strengt } \\
\text { h } \\
\text { (MPa) }\end{array}$ & $\begin{array}{l}\text { Elong } \\
\text { ation } \\
\text { in 50 } \\
\text { mm } \\
\text { gauge } \\
\text { length } \\
(\boldsymbol{\%})\end{array}$ & $\begin{array}{l}\text { Notch } \\
\text { tensile } \\
\text { strength } \\
\text { (MPa) }\end{array}$ \\
\hline AW & 286 & 320 & 7.22 & 258 \\
\hline AA & 312 & 335 & 6.37 & 272 \\
\hline STA & 329 & 358 & 5.82 & 288 \\
\hline
\end{tabular}

\section{CONCLUSIONS}

The effect of post-weld aging treatment on tensile properties, and microstructures of GTAW welded AA2519 T87 aluminium alloy has been investigated. The following conclusions can be made:

1. The high strength armour grade AA2519 T87 aluminium alloy plate of thickness had welded successfully at optimized parameter of welding current $145 \mathrm{~A}$ at welding speed $2 \mathrm{~mm} / \mathrm{sec}$.

2. Post weld aging treatment that results in regain of fine strengthening precipitates enhances strength by $4.6 \%$ in AA condition and $11.8 \%$ in STA condition.

3. Joint efficiency increased from $66 \%$ to $69 \%$ in AA condition and $74 \%$ in STA condition.

\section{ACKNOWLEDGEMENTS}

The author wish to express his gratitude to Dr. V. Balasubramanian, Professor \& Director, Centre for Materials Joining \& Research (CEMAJOR), Department of Manufacturing Engineering Annamalai University, for providing the facilities of Welding and Material Testing Laboratories to carry out this investigation and to S.Sree Sabari Research Scholar and Dr S.Malarvizhi Associate Professor for providing material for this investigation

\section{REFERENCES}

[1] Campbell FC. Manufacturing technology for aerospace structural materials. Elsevier; 2006.

[2] Tolga Dursun, Costas Soutis Recent developments in advanced aircraft aluminium alloys Elsevier; 2013

[3] Chaitanya Sharma, D.K. Dwivedi, Pradeep Kumar, Influence of in-process cooling on tensile behaviour of friction stir welded joints of AA7039, Materials Science \& Engineering A 556 (2012) 479-487.

[4] N.U. Deshpande, A.M. Gokhale, D.K. Denzer, and J. Liu: Metall. Mater. Trans. A, 1998, vol. 29A, pp. 1191-1201.

[5] Little RL. Welding and welding technology. New Delhi: Tata McGraw-Hill; 1990.

[6] Nadkarni SV. Modern arc welding technology. New Delhi: Oxford and Indian Book House; 1996.

[7] Khanna OP. Welding technology. New Delhi: Khanna Publishers; 1995.

[8] Kim HT, Nam SW. Solidification cracking susceptibility of high strength aluminium alloy weldment. Scripta Mater 1996:1139-45.

[9] Manti R, Dwivedi DK, Agarwal A. Pulse TIG welding of two Al-Mg-Si alloys. J Material Engg Perform 2008;17(5):667-73.

[10] V. Ravisankar, V. Balasubramanian, C. Muralidharan, Selection of welding process to fabricate butt joints of high strength aluminium alloys using analytic hierarchic process, Materials and Design 27 (2006) 373-380

[11] S. Malarvizhi, V. Balasubramanian, Effect of welding processes on AA2219 aluminium alloy joint properties, Trans. Nonferrous met. Soc. China 21(2011), 962-973.

[12] Menzemer C, Lam PC, Srivatsan TS, Wittel CF. Investigation of fusion zone microstructures of welded aluminum alloy joints. Mater Lett 1999;41:192-7.

[13] Lakshminarayanan AK, Balasubramanian V, Elangovan K. Effect of welding processes on tensile properties of AA6061 aluminium alloy joints. Int J Adv Manuf Tech 2009;40:286-96

[14] Hakan Aydın, Ali Bayram, Agah Uguz, Kemal Sertan Akay, Tensile properties of friction stir welded joints of 2024 aluminum alloys in different heat-treated-state, Materials and Design 30 (2009) 2211-2221.

[15] P.B. Berbon, W.H. Bingel, R.S. Mishra, C.C. Bampton, M.W. Mahoney, Friction stir processing: a 
tool to homogenize nanocomposites aluminum alloys, Scripta Mater. 44 (2001) 61-66.

[16] W.B. Lee, Y.M. Yeon, S.B. Jung, The improvement of mechanical properties of friction stir welded A356 Al alloy, Mater. Sci. Eng. A355 (2003) 154-159.

[17] Tianwen Zhao, Yanyao Jiang, Int. J. Fatigue 30 (2008) 834-849.

[18] T.S. Srivatsan, S. Anand, S. Sriram, V.K. Vasudevan, Materials Science and Engineerng A281 (2000) 292-304.

[19] Balasubramanian V, Ravisankar V, Madhusudhan Reddy G. Effect of post weld aging treatment on fatigue behaviour of pulsed current welded AA7075 aluminium alloy joints. J Mater Eng Perform 2008;7(2):224-33.

[20] M. Temmara , M. Hadji, T. Sahraoui Effect of post-weld aging treatment on mechanical properties of Tungsten Inert Gas welded low thickness 7075 aluminium alloy joints Materials and Design 32 (2011) 3532-3536.

[21] Ma T, Den Ouden G. Softening of Al-Zn-Mg aluminium alloys due to welding. J Mater Sci Eng A 1999;A 266:198-204 